\title{
Functional Status of Thyroid Gland in Hospitalized Children With Down's Syndrome
}

\author{
RABI BISWAS ${ }^{1}$, ABU SAYED MUNSI ${ }^{2}$, MANZOOR HUSSAIN³ ${ }^{3}$ MD. JAHANGIR ALAM ${ }^{4}$, \\ ASM NAWSHAD UDDIN AHMED ${ }^{5}$
}

\begin{abstract}
Background: Over one-hundred and thirty years ago a link between Down's syndrome and thyroid disease had been proposed. The additive effects of this co-morbid condition leads to further amplification of the clinical problems in these children with Down's syndrome. While several international studies have shown association of thyroid dysfunction with Down's syndrome, there is paucity of available data from Bangladesh.
\end{abstract}

Objective: The purpose of this study was to know the frequency of thyroid dysfunction in Down's syndrome children below the age of 12 years in our setting and to correlate the features of Down's syndrome with those of thyroid dysfunction.

Methods: A cross-sectional study was carried out on 40 patients of Down's syndrome admitted at Dhaka Shishu Hospital from January 2014 to March 2015. Diagnosis of Down's syndrome was considered clinically with or without confirmation by karyotyping. Thyroid function was assessed by serum $\mathrm{FT}_{4}$ and $\mathrm{TSH}$.

Results: All 40 patients enrolled were below 5 years and most of them $(72.5 \%)$ were within 12 months of age. Twenty-one cases were male and 19 were female. Hypothyroidism was found in 6 cases (15.0\%), of which 4 (10.0\%) had compensated hypothyroidism. Hyperthyroidism was not observed in any of the cases. There was no significant sex difference.

Conclusion: Hypothyroidism was frequently associated in children with Down's syndrome in our setting. It thus seems necessary to screen all children of Down's syndrome for thyroid dysfunction.

Key words: Down's syndrome, hypothyroidism.

\section{Introduction}

Down's syndrome (DS) is the most common chromosomal abnormality in live born infants, and is the most frequent genetic cause of mental retardation. It is a genetic disorder caused by the presence of a third copy of the whole, or a critical part, of chromosome 21 (trisomy 21). Global live-birth rates

1. Assistant Professor, Department of Paediatric Endocrinology and Metabolic Disorders, BICH, Dhaka Shishu Hospital

2. Assistant Professor, Department of Paediatric Cardiology, $\mathrm{BICH}$, Dhaka Shishu Hospital

3. Professor and Head, Department of Paediatric Medicine and Paediatric Cardiology, BICH, Dhaka Shishu Hospital

4. Professor, Department of Paediatric Rheumatology, $\mathrm{BICH}$, Dhaka Shishu Hospital

5. Professor, Department of Paediatric Endocrinology and Metabolic Disorders, BICH, Dhaka Shishu Hospital

Correspondence: Dr. Rabi Biswas, E-mail: rabibiswasdr@gmail.com for DS ranges between 1.2 and 1.5 per 1,000 infants with no predilection for race or socioeconomic group. ${ }^{1,2}$

Down's syndrome is characterized by typical dysmorphic features, and is associated with an increased incidence of certain medical complications. The most common endocrine disorder associated with DS involves the thyroid gland. ${ }^{3}$ Individuals with DS exhibit a wide range of thyroid dysfunction. In general, thyroid disorders have been reported to have a prevalence of $3-54 \%$ in people with DS, with the frequency of thyroid dysfunction increasing with age. ${ }^{4}$ It is estimated that the lifetime prevalence of hypothyroidism in DS is $30-50 \% .{ }^{5}$ Subclinical or 'compensated' hypothyroidism $(\mathrm{SCH})$ is the most common form of thyroid dysfunction in DS, being 
reported in $25-32 \%$ of patients. ${ }^{6,7}$ Friedman et al showed that $20.3 \%$ of patients with DS had previously unrecognized hypothyroidism. ${ }^{8}$ Fort et al reported 12 cases of congenital hypothyroidism out of 1130 infants of DS with an incidence of 1:141 compared to 1:3800 in the general population. ${ }^{9}$

The forms of hypothyroidism found in individuals with DS include congenital hypothyroidism, subclinical or 'compensated' hypothyroidism, uncompensated, transient and primary hypothyroidism, central hypothyroidism, thyroxin-binding globulin deficiency and chronic lymphocytic thyroiditis. ${ }^{10}$ The diagnosis of hypothyroidism in DS is complicated by the overlap between thyroid-associated symptoms and clinical features of the syndrome. Although less common than primary hypothyroidism $(\mathrm{PH})$, hyperthyroidism is also more common in DS than in the general population, $1.4 \%$ of children with DS had thyrotoxicosis. ${ }^{8}$

There are no recommended thyroid function test (TFT) reference ranges for children with $\mathrm{DS}$, and doctors all over the world have had to continue treating their patients with DS based on local reference ranges derived from studies on the general population. In this study, we aimed at estimation of association of thyroid dysfunction in DS children who were admitted to a tertiary care hospital at Dhaka city.

\section{Materials and methods}

A cross-sectional study was carried out on 40 children with DS who were admitted at different units of Dhaka Shishu (Children) Hospital during January 2014 to March 2015. Down's syndrome was diagnosed clinically with their typical features. The physical findings considered in diagnosis of DS include: mongoloid facies, brachycephaly, depressed nasal bridge, upslanted palpabral fissures, epicanthic folds, protruding tongue, small low set ears, short neck, single simian crease, clinodactyly, hypotonia, wide space between big and 2nd toe (sandal gap) and delayed milestones of development. Patients who already were on thyroxin or anti-thyroid therapy were excluded from the study.

On enrolment, detailed history was obtained from the caregiver and thorough clinical examination including developmental assessment of every case was carried out by the investigator. Mental function was assessed by psychologist using psychometric tools of Bayley Scales of Infant Development (BSID-II) for children up to 3 years \& 6 months and by Weschler Preschool \& Primary Scales of Intelligence (WPPSI) for children up to 7 years of age. Mothers' age at pregnancy was recorded as per mother's statement. Free Thyroxin $\left(\mathrm{FT}_{4}\right)$, Thyroid Stimulating Hormone (TSH) levels and other investigations necessary for treatment of the individual patient were done. The technique of Automated Chemiluminescent Microparticle Immunoassay was adopted for the estimation of the thyroid hormones and thyrotropin. On the basis of above investigations patients were grouped as euthyroid, hyperthyroid, compensated hypothyroid or uncompensated hypothyroid. Investigations for associated conditions like serum bilirubin, Widal test, blood for culture and sensitivity, chest X-ray, Color Doppler Echocardiography, ultrasonography of abdomen, barium meal and enema study and bonemarrow aspiration were done to reach the final diagnosis in individual cases. Karyotyping was done whenever possible.

Definition of thyroid dysfunction was based on elevated TSH levels. TSH was accepted as elevated if serum TSH level was above 20,10 , and $5 \mathrm{mU} / \mathrm{L}$ in DS patients aged from birth to one week, eight days to one month, and those older than one month, respectively. Subclinical or compensated hypothyroidism was considered in cases with a TSH level between 5-10 $\mathrm{mU} / \mathrm{L}$ and normal free $\mathrm{T} 4\left(\mathrm{FT}_{4}\right)$ level. A diagnosis of uncompensated or overt hypothyroidism was made in infants/children with low $\mathrm{FT}_{4}$ levels and $\mathrm{TSH}$ levels $>10.1 \mathrm{mU} / \mathrm{L}$. Hyperthyroidism was defined as low TSH ( $<0.5 \mathrm{mU} / \mathrm{L}$ ) and high $\mathrm{FT}_{4}$ level. ${ }^{11}$

All collected data were entered into and analyzed by SPSS statistical software (version 12).

\section{Results}

Forty patients with Down's syndrome were included in the study, of which 21 (52.5\%) were male and 19 $(47.5 \%)$ female, male-female ratio was 1.1:1. Diagnosis of DS was confirmed by karyotyping in 10 patients. The youngest subject was 1 month old and the oldest was 54 months old. Most patients were in the age range of 2 months to 1 year. The age distribution of the enrolled cases is shown in Fig.-I. 


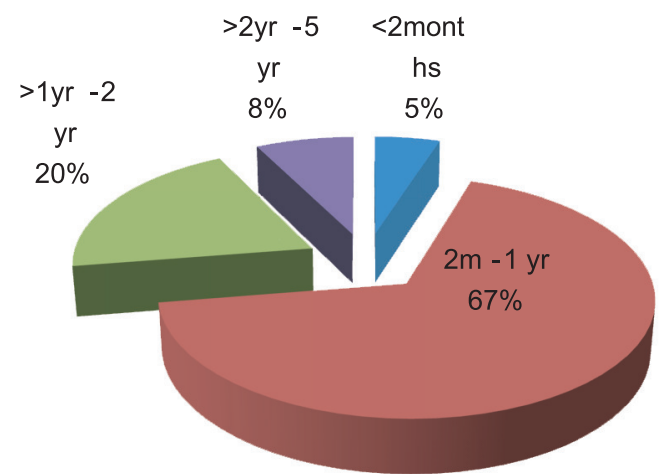

Fig.-I: Age distribution of Down's Syndrome children $(n=40)$.

Maternal age at pregnancy was recorded, which ranges from 25 to 39 years. Highest numbers (47.5\%) of mothers were between $30-<35$ years age group and also a significant number $(25 \%)$ of mothers were of 35 years or above.

Most of the patients were admitted for illness not related to thyroid dysfunction. Primary reasons for hospital admission were documented (Table-I), where $70 \%$ of cases admitted with congenital heart diseases with complications, of which Atriovetricular septal defect $(20 \%)$, Ventricular septal defect $(15 \%)$ and multiple cardiac lesions (30\%) were more commonly identified.

Among the features of Down's syndrome mental retardation and upslanted palpebral fissures were present in all the cases. Among the major physical findings for diagnosis of DS, epicanthic fold - $88 \%$, brachycephaly $-84 \%$, simian crease $-66 \%$, clinodactyly - $63 \%$, hypotonia - $50 \%$ and sandle gap - $50 \%$ were documented. The individual anthropometric measurements were all within the $25^{\text {th }}$ and $75^{\text {th }}$ percentiles for the matched age and sex. Developmental delay was noted in almost all cases, although it was the reason for admission in only $10 \%$ cases.

Distinguishable clinical features in favour of congenital hypothyroidism were seen only in two cases (33\%), one with persistent neonatal jaundice and one had constipation along with large tongue. Tachycardia and cardiomegaly were present in 28 cases who were presented with congenital heart defects with or without pneumonia. One of the cases had associated congenital gastrointestinal anomalies (duodenal atresia). A plain chest radiograph of each child was taken and cardiomegaly was observed in all who were admitted with cardiac defects, later congenital heart diseases were confirmed by color Doppler echocardiography. Consolidation was seen in two cases of pneumonia.

The mean TSH value was $6.85 \pm 12.56 \mathrm{mU} / \mathrm{L}$ and mean $\mathrm{FT}_{4}$ level $0.79 \pm 0.78 \mathrm{ng} / \mathrm{dL}$. Six cases $(15.0 \%)$ were found to have hypothyroidism, out of which 4 $(10.0 \%)$ were subclinical or compensated hypothyroidism i.e., raised TSH values in the face of normal $\mathrm{T}_{4}$ levels, while only $2(5.0 \%)$ were uncompensated or overt hypothyroidism. Out of six hypothyroidism cases, $4(10.0 \%)$ were male and $2(5.0 \%)$ female. In the rest $34(85.0 \%)$ children, including $17(42.5 \%)$ boys and 17 (42.5\%) girls, the values of the $\mathrm{FT}_{4}$ and $\mathrm{TSH}$ levels were within the physiological limits. None of our patients was found to have hyperthyroidism (Table-II).

Table-I

Primary reasons for hospital admission of Down's Syndrome $(n=40)$

\begin{tabular}{lcc}
\hline Reasons for Hospital Admission & Number & Percentage \\
\hline Congenital heart disease with pneumonia & 22 & 55 \\
Congenital heart disease with heart failure & 5 & 12.5 \\
Developmental delay & 4 & 10 \\
Pneumonia & 2 & 5 \\
Enteric fever & 1 & 2.5 \\
Acute gastroenteritis & 1 & 2.5 \\
Congenital heart disease with infective endocarditis & 1 & 2.5 \\
Hirschsprung disease & 1 & 2.5 \\
Leukaemia & 1 & 2.5 \\
Duodenal atresia & 1 & 2.5 \\
Persistent neonatal jaundice & 1 & 2.5 \\
\hline
\end{tabular}


Table-II

Distribution of the thyroid status in the Down's syndrome cases $(n=40)$

\begin{tabular}{lccccc}
\hline Category & $\begin{array}{c}\text { DS patients } \\
\mathrm{n}(\%)\end{array}$ & $\begin{array}{c}\text { Euthyroid } \\
\mathrm{n}(\%)\end{array}$ & $\begin{array}{c}\text { Compensated } \\
\text { hypothyroid } \mathrm{n}(\%)\end{array}$ & $\begin{array}{c}\text { Uncompensated } \\
\text { hypothyroid } \mathrm{n}(\%)\end{array}$ & $\begin{array}{c}\text { Hyperthyroid } \\
\mathrm{n}(\%)\end{array}$ \\
\hline Total no. & $40(100)$ & $34(85.0)$ & $4(10.0)$ & $2(5.0)$ & 0 \\
Male & $21(52.5)$ & $17(62.5)$ & $2(5.0)$ & $2(5.0)$ & 0 \\
Female & $19(47.5)$ & $17(21.9)$ & $2(5.0)$ & 0 & 0 \\
\hline
\end{tabular}

The age distribution of hypothyroidism cases is shown in Table-III.

Table-III

Age-wise distribution of the thyroid status in Down's syndrome cases ( $n=40)$

\begin{tabular}{lccc}
\hline Age group (months) & No. of case & Hypothyroid $\mathrm{n}(\%)$ & Euthyroid $\mathrm{n}(\%)$ \\
\hline $0-12$ & 29 & $5(17.2 \%)$ & $24(82.8 \%)$ \\
$>12-24$ & 8 & $1(12.5 \%)$ & $7(87.5 \%)$ \\
$>24-60$ & 3 & $0(0 \%)$ & $3(100 \%)$ \\
\hline
\end{tabular}

Table-IV shows the description of 6 patients identified as hypothyroidism biochemically includes their age, sex, TSH and FT4 level and type of hypothyroidism.

Table-IV

Description of patients diagnosed as hypothyroidism ( $n=6)$

\begin{tabular}{lcccl}
\hline Age (months) & Sex & $\mathrm{TSH}(\mathrm{mU} / \mathrm{L})$ & $\mathrm{FT}_{4}(\mathrm{ng} / \mathrm{dL})$ & Type of hypothyroidism \\
\hline 2 & Male & 54 & 0.3 & Uncompensated hypothyroidism \\
6 & Male & 63 & 0.42 & Uncompensated hypothyroidism \\
10 & Female & 18.4 & 0.87 & Compensated hypothyroidism \\
12 & Male & 11.6 & 1.1 & Compensated hypothyroidism \\
12 & Female & 18.4 & 0.87 & Compensated hypothyroidism \\
18 & Male & 14.8 & 0.72 & Compensated hypothyroidism \\
\hline
\end{tabular}

\section{Discussion}

Patients with DS have various medical problems including thyroid dysfunction. The majority of thyroid problem is $\mathrm{PH}$, which may compromise the physical and mental development in patients with DS. Therefore, we planned to assess the thyroid function status in our 40 children with DS admitted with different reasons. Most of them were young infants and severely ill due to congenital heart diseases with complications, as only significantly ill children are admitted in tertiary care hospitals. So, our study population may not represent the overall DS cases of the country. Advanced maternal age is associated with high incidence of Trisomy, it is also reflected in our study. ${ }^{12}$

We found no sex difference (Pearson chi-square:0.568 and $p$-value: 0.451 ) with regard to the incidence of hypothyroidism, which is consistent with the findings of other studies. ${ }^{4,13}$ This is in contrast to previous observations among both children and adults with hypothyroidism, in whom a female preponderance was found. ${ }^{14}$ Most of our patients with $\mathrm{PH}$ did not have symptoms and signs that could be distinguished from those of DS, as the majority of the features are overlapping.

Thyroid dysfunction, particularly hypothyroidism, is very common in Down's syndrome, although the available data come mostly from cross sectional studies. The present investigation is also a crosssectional study of thyroid function in children and young individuals with Down's syndrome. Our finding of hypothyroidism $(15 \%)$ in patients with Down's syndrome is comparable with the prevalence rates of 
3-54\% reported earlier studies among patients with Down's syndrome of all ages. ${ }^{15-19}$ The variation in prevalence in these earlier studies might be related to the age variation among the studied subjects and/or to differences in diagnostic criteria.

The $17.2 \%$ prevalence of hypothyroidism in the age group $0-1$ year in the present study could well be taken as a reflection of the prevalence of congenital hypothyroidism, as it shown in other studies. ${ }^{20}$ van Trotsenburg AS et al observed that decreased $T_{4}$ concentration, left-shifted normal distribution, and mildly elevated TSH concentrations point to a mild hypothyroid state in newborns with Down's syndrome could support the existence of a Down's syndromespecific thyroid (regulation) disorder. ${ }^{21}$

In our study, compensated/subclinical hypothyroidism has been found to be the most common (four of six cases of elevated TSH), as it shown in other studies. ${ }^{6,7,22}$ Furthermore, transient hypothyroidism is the most common form of thyroid dysfunction observed in Down's syndrome patients. Mark Selikowitz in his longitudinal study observed that $40 \%$ of these cases of compensated hypothyroidism resolved spontaneously. ${ }^{23}$ Gibson PA et al also observed that $47 \%$ of subclinical hypothyroid Down's syndrome patients were subsequently found to have normal TSH levels after a gap of four to six years. ${ }^{24}$ We do not know whether our cases are transient type or not, as we could not follow up the enrolled cases.

Hyperthyroidism is rare $(1.4 \%)$ in DS children and is more common in children above 8 years, ${ }^{18}$ which usually associated with presence of thyroid antibodies. ${ }^{25}$ Hyperthyroidism was not observed in any of the cases included in the study, probably due to the fact that none of our study population was more than 5 years old and thyroid antibodies were not estimated in the present study as it was not included in the study protocol.

All TFTs performed on the patients with DS included in this study were considered valid for inclusion, although TFTs were performed during concurrent illness. It has been found that alterations in TFT results are common in the above situation, and can be misleading. ${ }^{26}$

Clinical features suggestive of congenital hypothyroidism were seen only in two cases $(33 \%)$ in our study, which may be due to the fact that most $(67 \%)$ of our hypothyroid cases are compensated type and this result is comparable with other study. ${ }^{13}$

\section{Conclusion}

Hypothyroidism is frequently associated in Bangladeshi children with Down's syndrome. As the majority of these patients are asymptomatic for thyroid disorder, a screening program for thyroid dysfunction with all DS children is recommended. However, a longitudinal study with a larger sample size is necessary in order to validate the findings and also to detect whether the compensated hypothyroid cases are of transient type or not.

\section{References}

1. Hook EB. Chromosome abnormalities: Prevalence, risks and recurrence. In: Brock DLH, Rodeck $\mathrm{CH}$, Ferguson-Smith MA, editors. Prenatal Diagnosis and Screening. Edinburgh: Churchill Livingstone; 1992: p351-392.

2. Penrose LS, Smith GF. Down's Anomaly. Boston: Little Brown, 1966.

3. Pueschel SM, Jackson IMD, Giesswein P, Dean MK, Pezzullo JC. Thyroid function in Down syndrome. Res Dev Disabil. 1991;12:287-96.

4. Karlsson B, Gustafsson J, Hedov G, Ivarsson SA, Annéren G. Thyroid dysfunction in Down's syndrome: Relation to age and thyroid autoimmunity. Arch Dis Child. 1998;79:242-45.

5. Prasher VP. Down syndrome and Alzheimer's disease: Biological correlates. Abingdon, Oxon: Radcliffe Publishing, 2006.

6. Rubello D, Pozzan GB, Casara D. Natural course of subclinical hypothyroidism in Down's syndrome: Prospective study results and therapeutic considerations. J Endocrinol Invest. 1995;18:35-40.

7. Tüysüz B, Beker DB. Thyroid dysfunction in children with Down's syndrome. Acta Paediatr. 2001;90:1389-93.

8. Friedman DL, KastnerT, Pond WS, O'Brien DR. Thyroid dysfunction in individuals with Down syndrome. Arch Intern Med. 1989;149:1990-93.

9. Fort P, Lifshitz F, Bellisario R. Abnormalities of thyroid function in infants with Down syndrome. J Pediatr. 1984;104:545-49.

10. Coleman M. Thyroid dysfunction in Down syndrome: A review. Down Syndrome Research and Practice. 1994;2:112-15. 
11. Cebeci AN, Guven A, Metin Y. Profile of Hypothyroidism in Down's Syndrome. J Clin Res Pediatr Endocrinol. 2013;5:116-20.

12. Barlow GM, Chen XN, Shi Zy, Lyons GE, Kurnit DM, Celle L, et al. Down's syndrome and congenital heart disease: a narrowed region and a candidate gene. Genet Med. 2001;3:91-101.

13. Wong LM, Li KY, Tse K. Thyroid dysfunction in Chinese children with Down syndrome. HK J Pediatr (new series). 2004;9:114-17.

14. Railson ML, Dobyns, Keating FR, Rall JE, Tyler $\mathrm{FH}$. Occurrence and natural history of chronic lymphocytic thyroiditis in childhood. J Pediatr. 1975;86: 675-82.

15. Lobo EH, Khan M, Tew J. Community study of hypothyroidism in Down syndrome. Br Med J. 1980;280:1253-55.

16. Coleman M, Abbasi V. Down Syndrome and hypothyroidism: Coincidence or Consequence? Lancet. 1984;1:569.

17. Sare L, Ruvalcaba RHA, Kelley NC. Prevalence of thyroid disorder in Down syndrome. Clin Genet. 1978;14:154-58.

18. Loudon MM, Day RE, Due EM. Thyroid dysfunction in Down syndrome. Arch Dis Child. 1985;60:1149-51.

19. Sharav T, Collils RM, Baab PJ. Growth studies in infants and children with Down syndrome and elevated levels of thyrotropin. Am J Dis Child. 1988;142:48-54.
20. Shaw CK, Thapalial A, Nanda S, Shaw P. Thyroid dysfunction in Down syndrome. Kathmandu University Medical Journal. 2006;4:182-86.

21. van Trotsenburg AS, Vulsma T, vanSanten HM, Cheung W, de Vijlder JJ. Lower neonatal screening thyroxine concentrations in Down syndrome newborns. J Clin Endocrinol Metab. 2003;88:1512-15.

22. Moosa S, Segal DG, Christianson AL, Gregersen NE. Thyroid dysfunction in a cohort of South African children with Down syndrome. S Afr Med J. 2013;103:966-70.

23. Selikowitz M. Five year longitudinal study of thyroid functions in children with Down syndrome. Dev Med Child Neurol. 1993;35:396401.

24. Gibson PA, Newton RW, Selby K, Price DA, Leyland K, Addison GM. Longitudinal study of thyroid function in Down's syndrome in the first two decades. Arch Dis Child. 2005;90:557-58.

25. Gruneirode Papendieck L, Chiesa A, Bastida MG, Alonso G, Finkielstain G, Heinrich JJ. Thyroid dysfunction andhighthyroid stimulating hormone levels in children with Down's syndrome. J Pediatr Endocrinol Metab. 2002;15:1543-48.

26. Rossi WC, Caplin N, Alter CA. Thyroid disorders in children. In: Moshang T. Pediatric Endocrinology: editor. The Requisites in Pediatrics. St Louis, Miss.: Elsevier Mosby; 2004: p 171-190. 